N94- 35903

\section{INTEGRATION OF MAGNETIC BEARINGS IN THE DESIGN OF ADVANCED GAS TURBINE ENGINES}

\author{
A.F. Storace and D. Sood \\ General Electric Company \\ Aircraft Engines \\ J. P. Lyons and M. A. Preston \\ General Electric Company \\ Corporate Research and Development
}

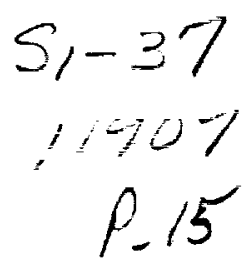

\title{
SUMMARY
}

Active magnetic bearings provide revolutionary advantages for gas turbine engine rotor support. These advantages include tremendously improved vibration and stability characteristics, reduced power loss, improved reliability, faulttolerance, and greatly extended bearing service life. The marriage of these advantages with innovative structural network design and advanced materials utilization will permit major increases in thrust to weight performance and structural efficiency for future gas turbine engines.

However, obtaining the maximum payoff requires two key ingredients. The first key ingredient is the use of modern magnetic bearing technologies such as innovative digital control techniques, high-density power electronics, highdensity magnetic actuators, fault-tolerant system architecture, and electronic (sensorless) position estimation. This paper describes these technologies. The second key ingredient is to go beyond the simple replacement of rolling element bearings with magnetic bearings by incorporating magnetic bearings as an integral part of the overall engine design. This is analogous to the proper approach to designing with composites, whereby the designer tailors the geometry and load carrying function of the structural system or component for the composite instead of simply substituting composites in a design originally intended for metal material. This paper describes methodologies for the design integration of magnetic bearings in gas turbine engines.

\section{INTRODUCTION}

The development of active magnetic bearings (AMB) for advanced gas turbine engines is key to expanding present performance envelopes to achieve the goals of the IHPTET (Integrated High Performance Turbine Engine Technology) initiative; namely, doubling propulsion system capability by the turn of the century. The term active magnetic bearings includes the magnetic bearings (actuators), the controller, and the power electronics. The integration of active magnetic bearing rotor suspension and the high specific stiffness and strength primary load path structures which are integral to IHPTET propulsion systems provides a significant further opportunity to increase the structural efficiency, performance, reliability, and maintainability of advanced turbine engines. For example, the payoffs obtainable by this marriage of advanced structures/materials technologies with the revolutionary advantages of active magnetic bearings are exemplified by the integration of a ceramic fiber-filament reinforced titanium based metal matrix composite (MMC) main engine (fan) shaft with the precise bearing force control provided by magnetic bearing suspension. The main engine shaft operates in a very rigorous, complex loading environment. The loads acting on the main engine shaft include rotordynamic transverse loads, transverse, axial, and torsional loads due to

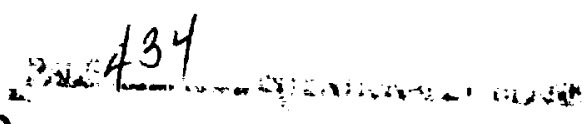


compressor rotor/low pressure turbine gas pressure loads and compressor flow distortion loads, maneuver loads, and blade-loss loads. Common practice for these shafts has been to use super alloy materials, such as Inconcel 718 or Marage 250. The strengths of these materials are satisfactory except their densities are also high which results in relatively low specific stiffness $(E / \rho)$ values. The main engine shaft tends to have significant participation in engine system imbalance response, and supercritical operation is sometimes required. In many cases, complex soft mount bearing support systems incorporating dampers are required. The use of active magnetic bearings and MMC shaft material provides a direct approach for achieving superior dynamic characteristics and high load capability. The high specific stiffness of the MMC shaft material and the larger rotor diameters made possible by the elimination of the DN number (bearing diameter in $\mathrm{mm} x$ shaft $\mathrm{RPM}$ ) restrictions of conventional rolling element bearings results in a dynamically rigid rotor at the high speeds required for advanced gas turbine engines. The result is that vibrational energy is driven into the magnetic bearings where tuning, damping, and active control strategies can be used to suppress the dynamic response for operating conditions extending into the extreme temperatures and speeds required for future advanced gas turbine engines.

The methodologies for the design integration of active magnetic bearings in the engine structural network to achieve a compact, simplified, and structurally efficient engine system are described in this paper. The elements of the advanced fault-tolerant active magnetic bearing system to be described herein include the magnetic bearings (which function as both high-density electromagnetic actuators and displacement transducers - in essence sensorless air gap estimation), the high-speed digital controller, and the high-density power electronics. The control algorithm for the digital controller has the capability to employ a variety of closed and open-loop (feed-forward) control strategies, dependent on the engine operating speeds, and external and internal engine loads. Also discussed are auxiliary bearings which are an additional element in the AMB system. They are needed as a back-up for the magnetic bearings, and to supplement the magnetic bearings for hard maneuvers and extreme loadings, such as bladeloss loads.

\section{ENGINE STRUCTURAL TAILORING FOR ACTIVE MAGNETIC BEARINGS}

To meet the exceedingly challenging performance goals of the IHPTET initiative, stringent rotor stage clearance control, engine weight reduction, high cycle temperatures, and higher rotor speeds will be required. The major increases required for the advanced turbine engine concepts in thermal efficiency, thrust/weight for fan engines, and power/weight for turboshaft engines will be obtained by adapting structural geometry for rotors, frames, cases, blades, and discs to take full advantage of advanced material characteristics such as those provided by metal matrix composites (MMC) and ceramic matrix composites (CMC).

Beyond the innovative structural arrangements and utilization of advanced materials, the incorporation of magnetic bearing rotor suspension provides a significant further capability to increase propulsion efficiency. Furthermore, the use of an Integral Starter/Generator (IS/G) mounted directly on the high pressure shaft provides on-board power for the magnetic bearings and engine starting capability 1 . A magnetic bearing engine with an IS/G forms one of the cornerstones of an "All-Electric" or "More-Electric" engine. The IS/G precludes the need for a power take-off (tower) shaft and an external gearbox to drive engine accessories (extemal generator, starter, pumps, actuators) such as shown in Figure 1 for present day engines. The magnetic bearing - IS/G combination provides for the virtual elimination of engine self-generated rotor whirling, elimination of the lube system required for rolling element bearings (refer to Figure 2), elimination of rotor dampers, engine structural simplification, engine weight reduction, potential for unlimited bearing service life, elimination of secondary engine power extraction, reduced vulnerability, and significantly improved reliability and maintainability. 


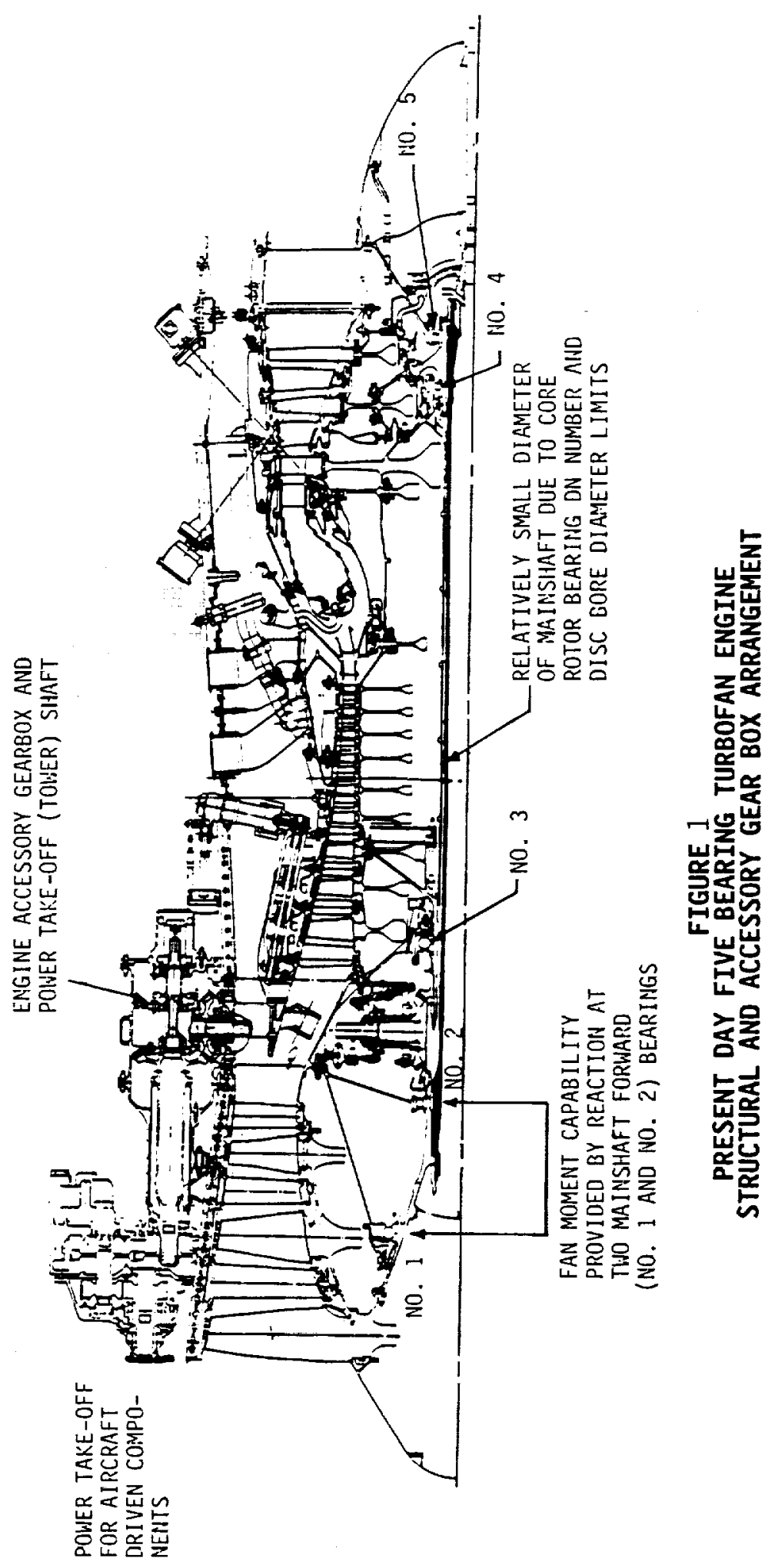




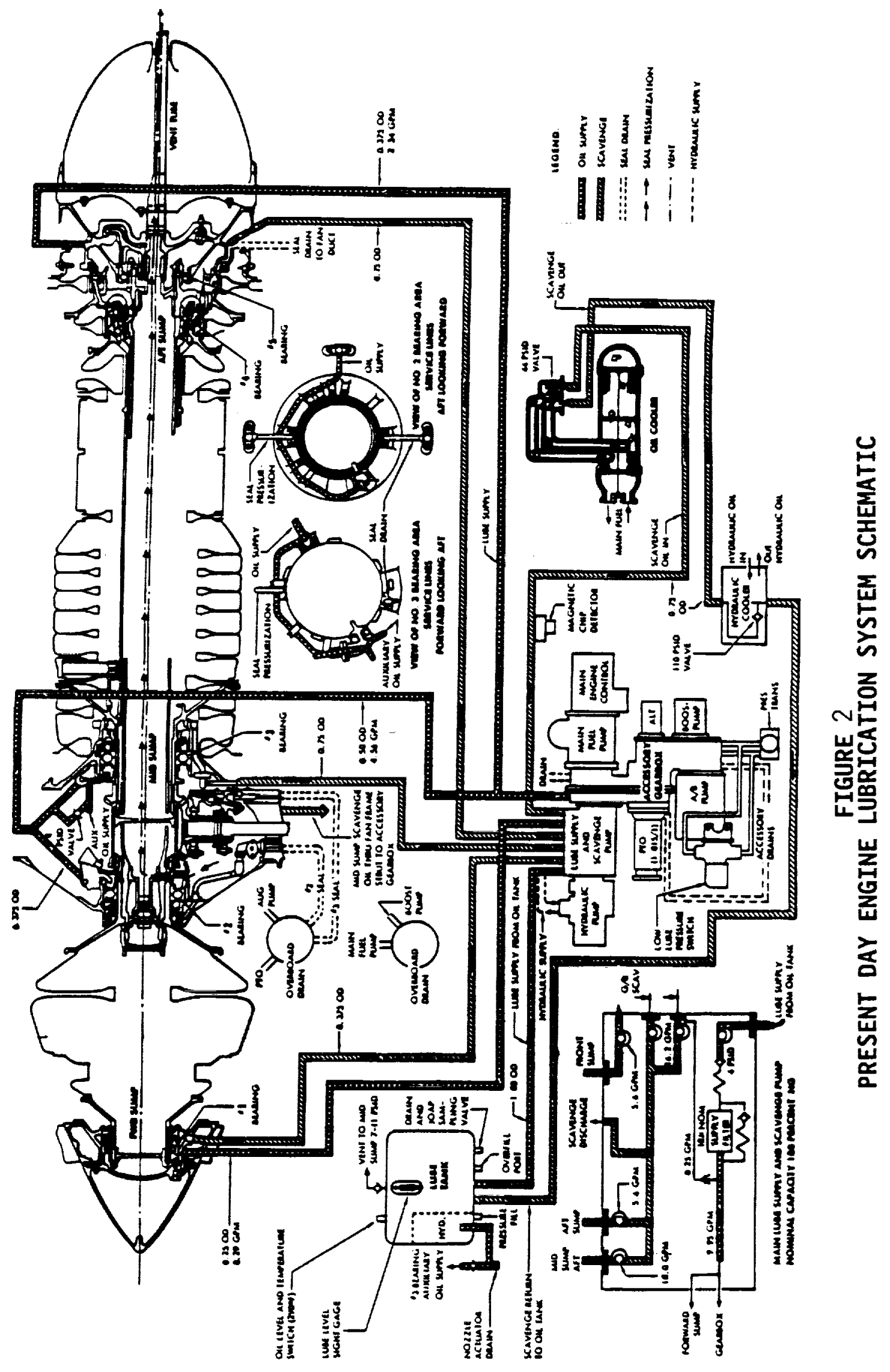


The synergism of magnetic bearings and improved component designs incorporating advanced materials permits the development of turbine engines with a fewer number of bearings while also achieving significant improvement in rotordynamics characteristics and greatly reduced sensitivity of rotor stage clearance closures due to maneuver loads. Consider the main engine or fan shaft. This shaft spans across the core engine and in conventional engines has a large length-to-diameter ratio. In order to avoid critical speed problems and unacceptable maneuver load deflections at the fan and low pressure turbine for fan engines, redundant mounting is used. Figure 1 shows a large, present day five bearing military engine which uses three rolling element bearings (Nos. 1,2, and 5) to support the main shaft. Couple support across the No. 1 and No. 2 bearings reacts the large overturning moment generated by the fan during inflight gyro maneuver conditions and provides the stiffness required to avoid fan nodding modes in the operating speed range. This couple support is needed to control fan tip deflection as very little moment carrying capability is provided by the main shaft aft of the two forward bearings due to its low bending stiffness. This low bending stiffness is caused by the relatively small outer diameter of the main shaft required to meet core rotor bearing DN number (approximately 1.5 million) and disk bore diameter limits. The bore diameters of the core rotor disks of present day engines are minimized to maintain the stresses in the monolithic material disks within allowable limits at the maximum engine speeds. However, when magnetic bearings are used, DN numbers approaching or exceeding 3.5 million (based on maintaining magnetic bearing rotor lamination stresses within allowable limits) are achievable. In addition, significantly increased allowable disk stress levels and the attendant larger disk bore diameters can be achieved through the use of circumferential fiber reinforced composite material, such as Titanium based MMC for the compressor disks, and ceramic matrix composite for the turbine disk.
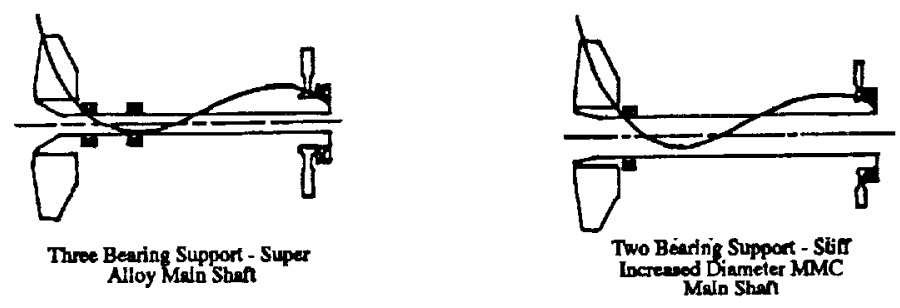

Figure 3. Main Engine Gyroscopic Loading Deflections

The need for three bearing support of the main engine shaft to prevent unacceptable fan pitching under gyro maneuver and dynamic loads is eliminated through the use of magnetic bearings and a high stiffness main shaft. Fabricating the main shaft from Ti $6 \mathrm{AL}-2 \mathrm{~S}_{\mathrm{n}}-4 \mathrm{Z}_{\mathrm{r}}-2 \mathrm{M}_{\mathrm{O}}$ matrix material reinforced with continuous ceramic (silicon carbide) fibers allows the obtainment of high shaft stiffness. Note that the metal matrix composite (MMC) material is not stiffer than super alloy materials presently used in turbine engine shafts. However, it has a lower density allowing larger main shaft diameters to be used to obtain high stiffness without a weight penalty. The increase in high pressure rotor bore diameters required to obtain sufficient main shaft stiffness to permit two bearing support (at each end of the shaft with the two forward-couple bearings replaced by a single bearing) requires core rotor bearing DN numbers in the range of 3.5 million - well within the capability of magnetic bearings. The equivalence between three bearing support and an increased stiffness main shaft supported by two bearings is shown in Figure 3 . In addition to controlling fan pitching due to gyro maneuver loads and avoiding fan nodding modes in the operating speed range, the high specific stiffness (E/e) MMC material reduces the participation of the main shaft mid-region in engine system criticals with the result that main shaft unbalance response sensitivity is further decreased.

Running the reinforcing fibers parallel to the axis of the main shaft results in the greatest improvement of shaft bending stiffness. However, in order to provide the required torsional strength, angle-ply fiber orientations are used. The MMC lamina are wrapped so that the fibers form a helix which advances along the shaft length. This scheme still provides a significant payoff in increased absolute and specific stiffness in the axial direction. References 2,3 discuss the benefits in gas turbine engine structural efficiency and performance achievable through the use of metal matrix composites with continuous fiber reinforcement in component structures. Table 1 shows a stiffness comparison of Ti $6-2-4-2 / \mathrm{SiC}$ angle-plied MMC material and selected super alloys at elevated temperature. Note the increased specific stiffness in the axial direction obtainable with angle-plied $\mathrm{Ti}$ 6-2-4-2/SiC MMC material. 


$\begin{array}{lllll} & \begin{array}{c}\text { TI 6-2-4-2/SIC } \\ \text { Angle Plied MMC }\end{array} & \text { INCO 718 } & \text { RENE'95 } & \text { MARAG } \\ & & & & \\ \text { Density }\left(\mathrm{lb} / \mathrm{in}^{3} \text { ) }\right. & 0.145 & 0.296 & 0.297 & 0.289 \\ 1000^{\circ} \mathrm{F} \mathrm{Modulus} \mathrm{(MSI)} & 25 & 25 & 27 & 21 \\ 1000^{\circ} \mathrm{F} \mathrm{E} / \rho \text { (in) } & 172 * 10^{-6} & 84 * 10^{-6} & 91 * 10^{-6} & 73^{*} 10^{-6}\end{array}$

Table 1. Stiffness/Weight Comparison of Titanium-Based MMC to Selected Superalloys

In addition to a stiff main shaft, the higher DN numbers made possible by magnetic bearings also permit a stiff high pressure or core rotor. This results in dynamically rigid rotors with the result that vibration energy is driven into the magnetic bearings. This permits a number of different control strategies to be effectively used to suppress rotor vibration over the complete operating spectrum. These control strategies will be discussed later in this paper.

It should be noted that auxiliary or back-up bearings are an integral part of the magnetic bearing design. These bearings are designed to operate at approximately half the clearance of the magnetic bearings and thus prevent damage to the magnetic bearings at touchdown. In addition to providing support during shipment, storage, and for all other non-operational time, the auxiliary bearings share momentary overloads due to shock and blade-loss, and provide support following magnetic bearing failure. There are two likely candidates for the auxiliary bearings. The first auxiliary bearing candidate is a hydrostatic gas bearing integrated with the magnetic bearing structure and configured to act in parallel continuously or be activated on demand. This gas bearing would be supplemented by a self lubricated sleeve bearing for shock- and extreme-load conditions as well as at low engine speeds (below idle). The second auxiliary bearing candidate is a dry-lubricated, high-temperature, rolling-element bearing designed to operate for short periods at above 3.0 million $\mathrm{DN}$ at temperatures above $800^{\circ} \mathrm{F}$. To dissipate the heat generated by the dry-lubricated bearing, cooling air will be supplied by engine bleed. Lubrication can be provided by a dry powder delivered to the bearing from an emergency canister activated when a loss of rotor control is sensed by the magnetic bearing controller. The following dry bearing configurations are candidates for auxiliary bearings: a hybrid with rolling elements and tungsten alloy races, a hybrid with rolling elements and intermetallic races, and an all fiber-reinforced-ceramic bearing.

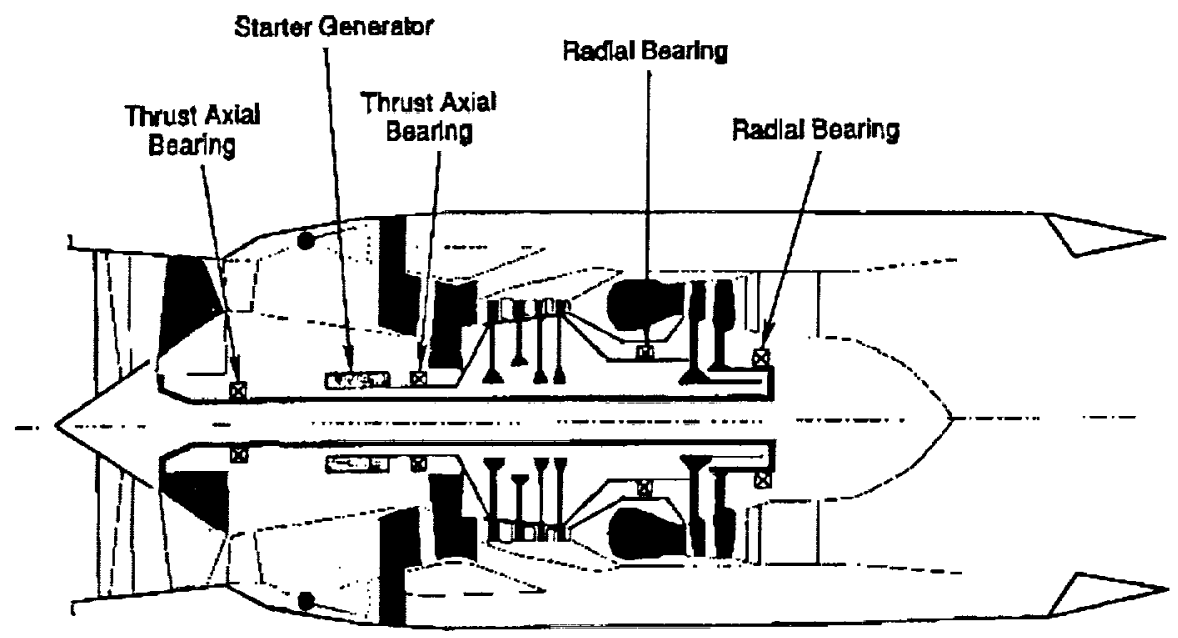

Figure 4. Advanced Four Bearing Turbofan Engine with Magnetic Bearings and Integral Starter/Generator 
Figure 4 shows a simplified engine structural network made possible by full magnetic bearing integration and incorporation of an integral starter/generator on the high pressure spool. These technologies permit a four bearing configuration, and the elimination of the lube system, power take-off shaft, and the external gearbox. In addition to significantly improved reliability and maintainability, the weight savings are substantial, amounting to more than 200 lbs for a large military engine.

\section{CONTROL ALGORITHMS}

A digital controller will be used to implement control algorithms for rotor stabilization and vibration reduction. It will be noted that a digital controller permits the easy change of control algorithms. Hence, a wide range of control options are easy to implement for the magnetic bearing suspension control system. The control strategies fall into two categories: Closed and Open Loop Control. The former is incorporated into the feedback loop and can impact stability of the active magnetic bearing system. The latter is a feed-forward method whereby external control forces are superimposed on the feedback control forces to reduce vibration. This method separates the rotor suspension and vibration control problems, and thus permits the feedback control to be designed solely to provide maximum stability.

Two approaches that can be used to implement closed loop control are adaptive stiffness/damping control, and the tracking notch filter method. The former method reduces vibration by critical speed tuning and vibration energy dissipation. This is accomplished by varying bearing stiffness and damping to eliminate resonances or to heavily suppress response at rotor critical speeds. This method can provide robust performance when the shaft/bearing system is subjected to external disturbances. For the latter closed loop method, a tracking notch filter is placed in the feedback loop to permit accommodation of synchronous disturbances. This causes the magnetic bearing to have greatly reduced stiffness and damping at the running speed, thus desensitizing the rotor to imbalance because it tends to spin about its inertial axis.

The open-loop control can be implemented as either an active vibration control scheme, or as a bearing synchronous force cancellation scheme for selected frequencies. Typically, for the former approach, vibration displacements are canceled at the magnetic bearing plane or at some other location, such as on the engine casing. This is a disturbance rejection method and is accomplished by the injection of open-loop forces which can be calculated using influence coefficients. In the latter open-loop approach, the force actuator commands can be adjusted so as to eliminate the synchronous component of these forces. This disturbance accommodation approach can be characterized as an open-loop notch filter as the bearings exert no active synchronous forces, which results in isolation of the rotor at the running frequency.

Effective control of the magnetic bearing/rotor system will require the implementation of a combination of the control elements discussed above. For example, active vibration control accomplished through the injection of openloop forces can be used for low speed operation (rotor start-up to idle speed) to cancel rotor synchronous vibration displacements at the magnetic bearing planes. In this scheme, the engine is modeled on line through the generation of dynamic influence coefficients which are used to construct reduced dynamic stiffness matrices used in the calculation of vibration canceling forces. One method to obtain the influence coefficients involves processing trial force signals injected at the magnetic bearings and the resulting response signals at discrete rotor speed points during exploratory accels/decels. This method is adaptive in that the amplitudes and phases of the corrective forces are dependent on the engine speed, vibratory characteristics, and imbalance levels, and the influence coefficients are updated to reflect changes in the engine system frequency response characteristics. The influence coefficients and measured response are then used to calculate corrective forces which are used in an open loop mode to cancel the synchronous response due to rotor imbalance. Since the synchronous response is highly correlated, it may be altered without feedback. Thus, the system stability is not affected by the open loop control. This active vibration control method would not be used for high speed operation because the injected forces needed to reduce displacement levels at the magnetic bearing sensors can actually increase the transmittal forces at the magnetic bearings in this speed regime. 
For operation above idle speed, the closed or open-loop notch filter method can be used to suppress synchronous vibration. This method is not suitable for low speed operation in the vicinity of the rigid body criticals (resulting from bearing stiffness suppression) because the synchronous imbalance response is basically uncontrolled in this speed regime.

\section{ELECTROMAGNETIC ACTUATORS}

Figure 5 shows a fault-tolerant radial magnetic bearing. The bearing uses 3 radial control axes which are made up of 12 electromagnetic stator poles organized into 6 force-producing pole-pairs with $60^{\circ}$ radial spacing. Two pole-pairs at $180^{\circ}$ radial separation combine to create a single control axis.

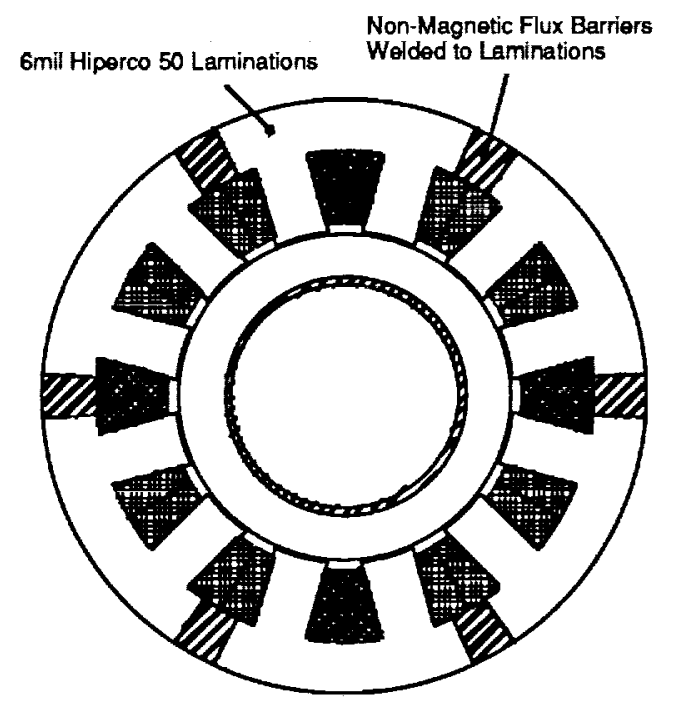

Figure 5 - Fault-Tolerant Radial Magnetic Bearing

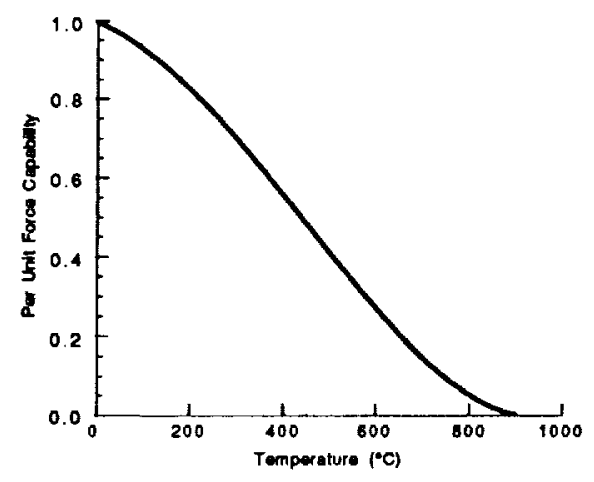

Figure 6 - Effect of Temperature on Cobalt-Iron Force-Production Capability

The stator core is segmented with non-magnetic sections in order to minimize the magnetic coupling between adjacent pole-pairs. The magnetic isolation provided by the stator segmentation will allow non-faulted force-actuation pole-pairs to continue functioning in the proximity of faulted magnetic poles. Since any 2 of the 3 (or more) control axes are sufficient to maintain rotor suspension, the third control axis in this magnetic structure provides inherent redundancy and given appropriate control measures, continued bearing operation in the presence of a variety of faults (e.g. faulted magnetic poles, power electronic shorts, phase power loss, etc.) is possible. Greater inherent redundancy/fault tolerance can be readily achieved by adding more than 3 axes of control.

This magnetic structure for the stator can be constructed using a stack of composite laminations as has been done for electric machine rotors 4,5 or by bonding solid non-magnetic segments to a stack of laminations as has also been done for electric machine rotors 4,5 . The bearing laminations are made from a Cobalt-Iron alloy which has superior magnetic, thermal degradation and mechanical properties, but is slightly more lossy than alternative materials. A maximum operating temperature is chosen as a compromise between bearing size and cooling requirements. Bleed air would be used to limit the temperatures. Figure 6 shows the effect of temperature on per unit force production capability of Cobalt-Iron laminations. 
The magnetic material used for rotors has to withstand the centrifugal force induced stresses at maximum rotor speed and maximum temperature. Cobalt-Iron in its normal anneal at $1550^{\circ} \mathrm{F}\left(840^{\circ} \mathrm{C}\right)$ has a $0.2 \%$ yield of $44 \mathrm{ksi}$ up to $300^{\circ} \mathrm{F}\left(150^{\circ} \mathrm{C}\right)$. At temperatures of $500^{\circ} \mathrm{F}\left(260^{\circ} \mathrm{C}\right)$ this reduces to less than $40 \mathrm{ksi}$. A second material option is the $1350^{\circ} \mathrm{F}\left(740^{\circ} \mathrm{C}\right)$ anneal version of the same Cobalt-Iron. This material has a $0.2 \%$ yield of better than $80 \mathrm{ksi}$ at $140^{\circ} \mathrm{C}$ and remains much stronger at higher temperatures $\left(75 \mathrm{ksi}\right.$ at $\left.500^{\circ} \mathrm{F}\right)$. The price paid for the higher strength is 5 to $10 \%$ reduction in maximum force production capability and higher rotor eddy current losses.

The stator windings must withstand temperatures significantly higher than the magnetic material since heat transfer from the windings to the stator is generally poor. A silicon-mica based insulation system, Thermidur, as demonstrated by Siemens, Germany, for $10,000 \mathrm{hrs}$ life at $752^{\circ} \mathrm{F}$ with occasional excursions to $932^{\circ} \mathrm{F}$ is preferred.

\section{ELECTRONIC (SENSORLESS) POSITION ESTIMATION}

The rotor position sensors used with magnetic bearings are a major cost and reliability handicap. It is possible to use the magnetic bearing actuators themselves as magnetic position sensors thereby eliminating the need for external position sensors. This can be done using one of two methods, inductance or flux-current, which are based on the magnetic model shown in Figure 7.

The inductance measurement measures time rate of change of current to estimate inductance which can be functionally related to rotor-stator airgap. There are two problems with this approach. First the rate of change of current is dependent on airgap velocity as well as rate of change of current and this causes large errors in the airgap estimate for high-speed bearings. Second, when the soft magnetic materials in the bearing begin to saturate, the relationship between inductance and airgap becomes multi-valued; that is there are many possible airgaps associated with a given inductance. The actuator current can be used to reduce this to two choices, but some knowledge of position history is required to choose the correct airgap.
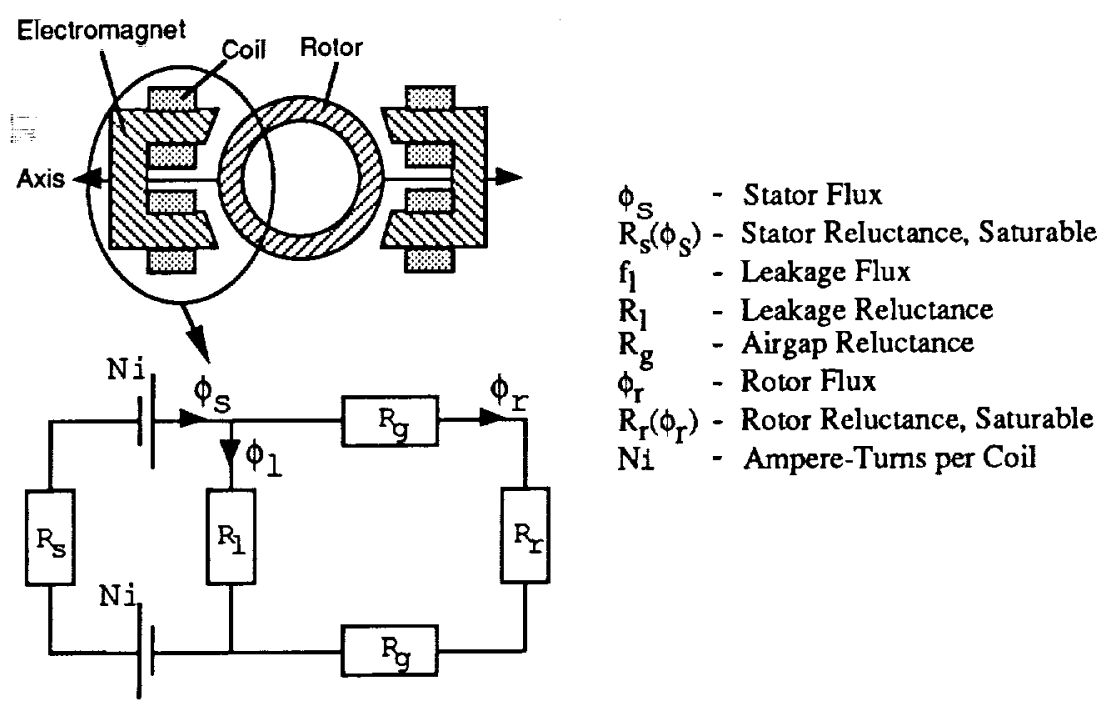

Figure 7 - Magnetic Model of Fault-Tolerant Bearing 
The flux-current method uses the relationship $\phi_{s}=\int \frac{v-i r}{N} d t$ to determine the flux in an excited winding. Then, given the actuator current and a suitable magnetic model of the actuator, a unique rotor-stator airgap can be determined. This method works regardless of airgap velocity or magnetic saturation. The primary difficulty here is in maintaining an accurate flux estimate where the excitation waveform is nol cyclic and the required integrator cannot be reset periodically. This method has been used successfully with switched reluctance motors 6,7 .

\section{FAULT-TOLERANT ENGINE ELECTRICAL SYSTEM}

Figure 8 illustrates a conceptual electric system for an advanced aircraft engine. This is a fault-tolerant system relying on 3 independent $270 \mathrm{vdc}$ buses for distribution amongst a variety of loads, including active magnetic bearing (AMB) controls and power electronics.

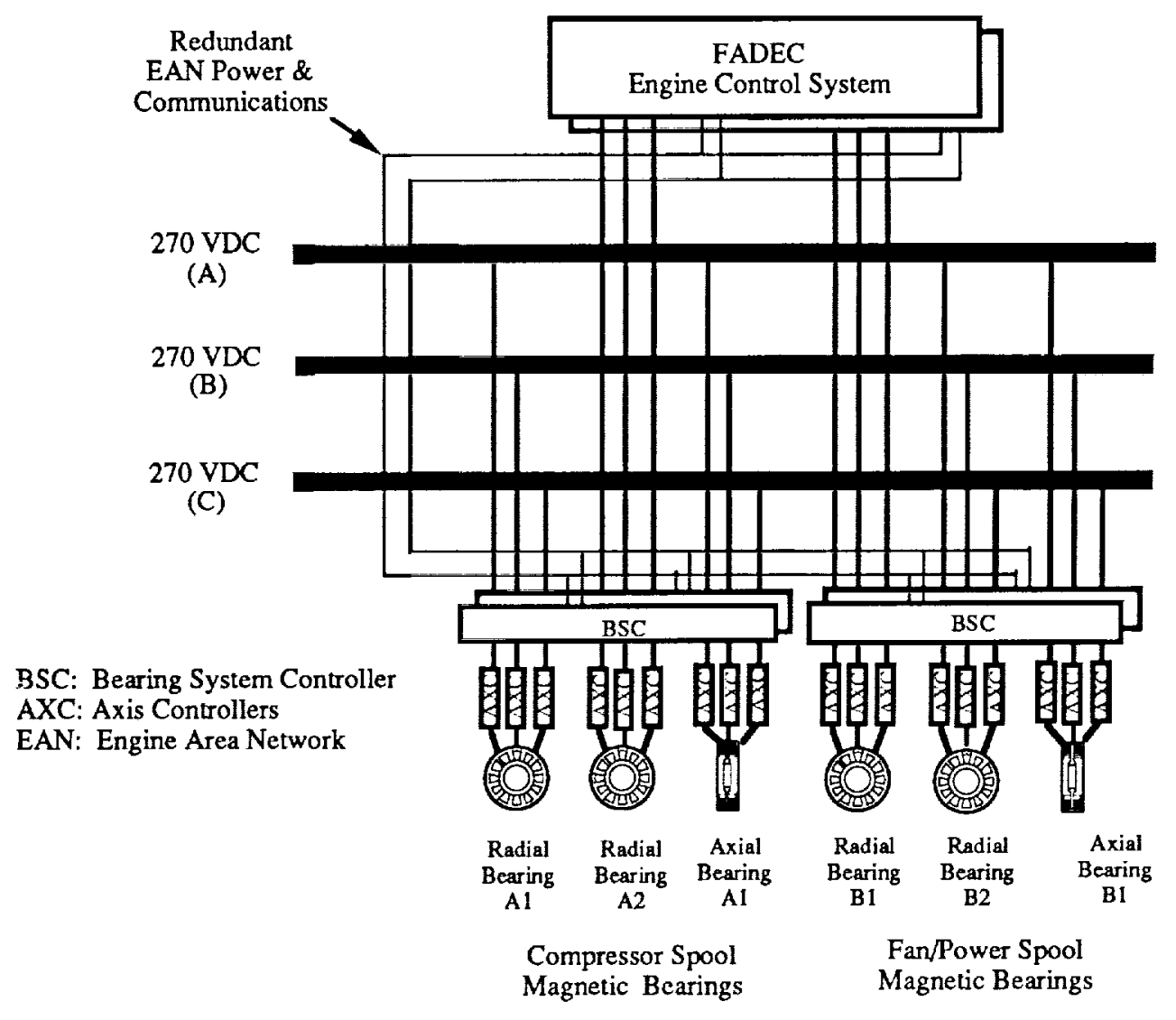

Figure 8. More Electric Engine Electrical System

The 3 distribution buses would appear to represent a conventional triple modular redundancy with $200 \%$ overcapacity, but this is not the case. The electric distribution system would be designed for $50 \%$ over-capacity, i.e., each bus designed for $50 \%$ of the needed system capacity, thereby requiring 2 of the 3 buses at any time in order to avoid system failure.

The radial active magnetic bearings are configured with 3 magnetically independent control axes per bearing placed at 60 degrees radial separation. These 3 control axes cooperate to control the radial rotor position such that 
- control can be maintained with only 2 of the control axes functioning. Each of the 3 bearing control axes are powered from a different dc bus; therefore the radial bearings require 2 active dc distribution buses in order to maintain rotor position control. The total available force vector is angle dependent, but is a minimum of 0.866 times the force capacity of a single control axis.

The axial active magnetic bearings are configured in a similar fashion with 3 magnetically independent control axes, each control axis with 50\% force capability - thus 2 of the 3 available control axes are required for rated thrust loading. Each of the axial control axes are also fed from different dc electrical distribution buses.

\section{MAGNETIC BEARING CONTROLS}

The magnetic bearing controls consist of 2 hierarchical levels: a supervisory level - Bearing System Controller (BSC), and an actuation level - Axis Controller (AXC). The supervisor controllers are configured in a duplex fault tolerant configuration, with one supervisor in active control and the second in an active standby mode. Each Bearing System Controller is configured to control one engine spool (8 control axes).

The actuation controllers are essentially smart, self-protecting, power amplifiers capable of exciting a single independent AMB axis (2 electromagnetic windings, + and -). A radial bearing will thus require 3 AXC's. Each actuation controller is capable of accepting commands from and delivering feedback information to multiple supervisors, thereby enabling redundancy at the supervisor level.

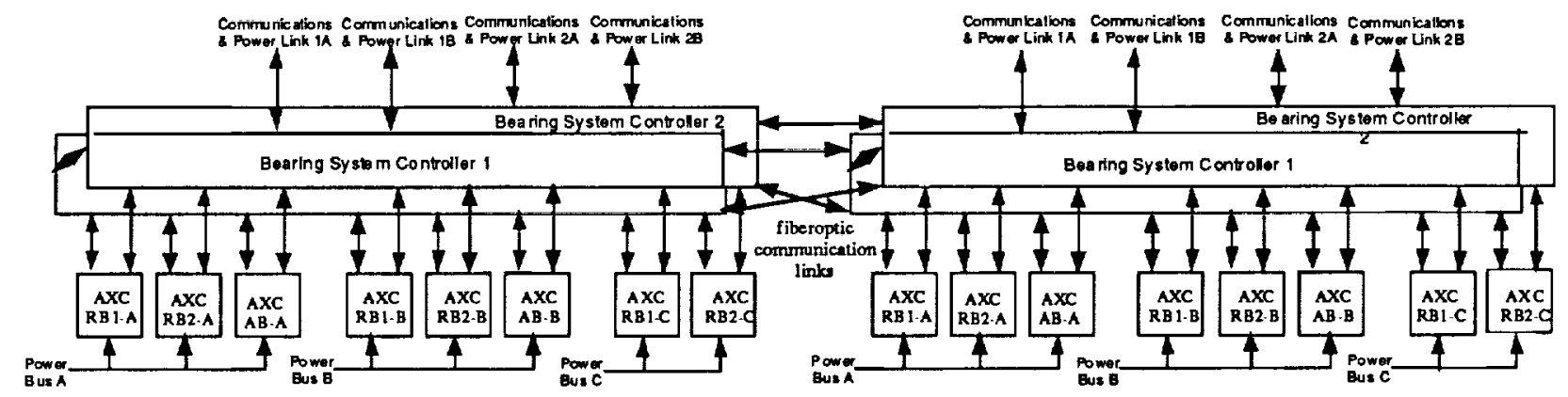

Figure 9. Twin Spool Active Magnetic Bearing Control System with Duplex Supervisor

The duplex supervisory controllers are essentially an extension of the dual-redundant engine controller (FADEC) acting as intelligent high-bandwidth actuators. The supervisor controllers are powered from the FADEC control power and communicate with the FADEC via a multi-drop Engine Area Network (EAN). Two redundant EAN communication/control power channels are provided. An actuation controller is powered, along with the power electronic switches it controls, directly from an individual dc electrical distribution bus. Communication between the supervisory and actuation levels is accomplished in a manner to maintain electrical isolation e.g. fiberoptic communication links.

Figure 9 illustrates the active magnetic bearing controller architecture for a twin spool engine. Each spool has a duplex supervisory Bearing System Controller which is responsible for coordinated control of the rotor position, vibration, and imbalance - this coupled control will execute at a $6.7 \mathrm{kHz}$ task execution rate and transmit new force commands to the axis controllers. The Axis Controllers are responsible for force control \& linearization, gap 
position \& velocity inference, fault detection \& isolation - the axis controller will execute at a $20 \mathrm{kHz}$ task execution rate which results in power electronic switching at an equivalent frequency.

Each axis controller is capable of accepting 2 command streams from each of the duplex Bearing System Controllers via high-bandwidth half-duplex serial communication channels. The controlling supervisor will transmit a current state information packet, once per control iteration, to the active standby BSC both as a heartbeat indicator and to enable a smooth transition to the backup supervisor if required. The supervisory controllers for each engine spool are capable of communicating once per control iteration with each other to transmit required dynamic coupling information. The BSC peer-peer communications are high-bandwidth full duplex serial communications links. The BSC's are also required to communicate with the FADEC over slower half-duplex communication links.

\section{AMB SYSTEM MODELING AND SIMULATION}

Figure 11 illustrates a SimPEl simulation of the AMB control system. SimPEl (Simulator for Power Electronics) is an object-oriented dynamic simulator developed by GE CR\&D. SimPEl uses explicit numerical integration procedures to predict the responses of dynamic systems. Each of the physical elements of an active magnetic bearing system have been included, including the three 270 vdc buses (amb-bus in Fig. 11), axis controller power electronic converters (axc-pe), radial \& axial bearing magnetic actuators ( $\mathrm{rb}$ and $\mathrm{ab}$ ), rotor dynamics (rotor), axial \& radial catcher bearings (rcb and acb), bearing mechanical support structures (stator), and the AMB control system itself (amb_control). The rotor model includes rigid body rotor dynamics which are currently being extended to include flexible-rotor modeling. The magnetic bearings are modeled using the model shown in Figure 7 . Figure 10 illustrates simulated radial bearing force waveforms produced by SimPEl.

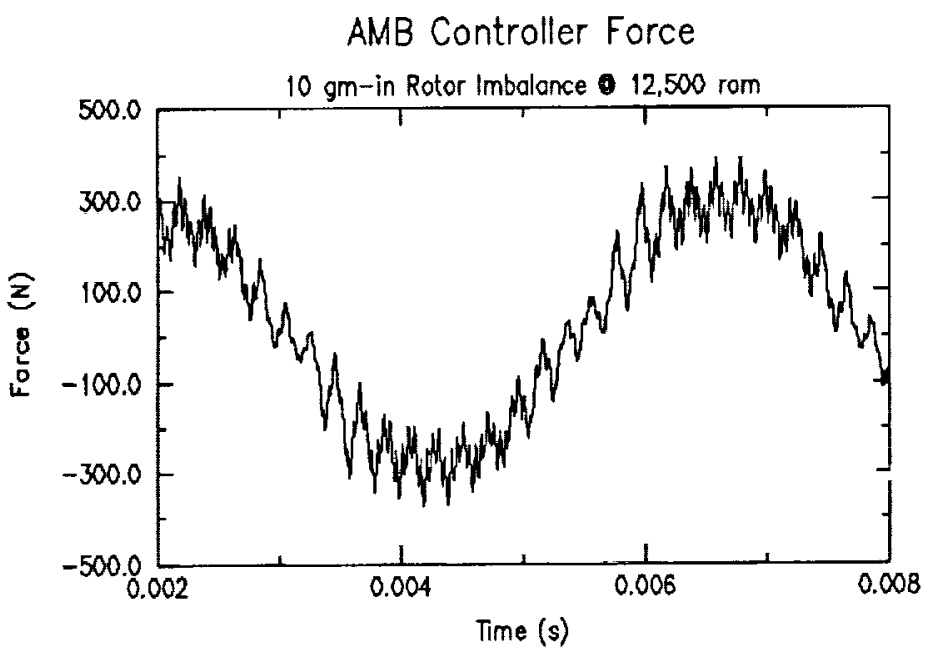

Figure 10. Force Waveforms with $20 \mathrm{kHz}$ Ripple 


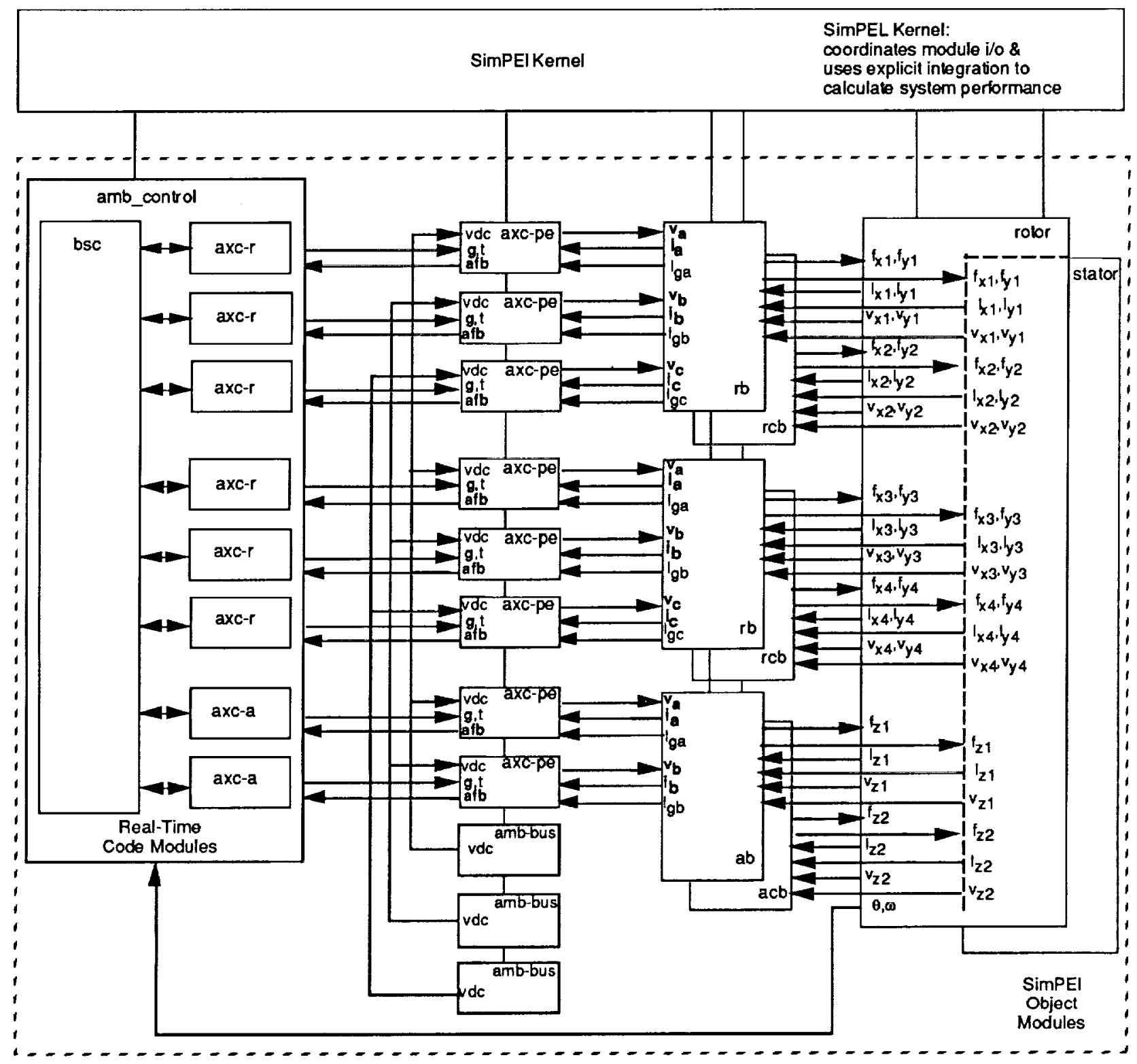

Figure 11. SimPEl Active Magnetic Bearing System Simulation

The SimPEl amb_control module contains the target source codes for the BSC and AXC digital signal processor modules. These source codes enable simulated rotor suspension along with axis availability dependent force and gap transformations to and from orthogonal $y z$ control axes and coupled $a b c$ control axes. The SimPEl simulation as configured allows extensive debugging of the control source codes under simulated conditions, prior to the availability of the target hardware. 


\section{GE MAGNETIC BEARING TEST RIG}

The test rig shown in Figure 12 has been developed by General Electric for validation testing of advanced magnetic bearings and digital controls/power electronics systems. This effort will encompass programs for the use of magnetic bearings for marine and aeroengine main shaft support and applications for stationary power plant turbomachinery and generator rotor support. The conventional proximity sensors depicted in Figure 12 will be used initially for rotor displacement calibration measurements. Later, the sensorless air gap estimation technique based on utilizing the magnetic bearings as both force actuators and displacement transducers will be used.

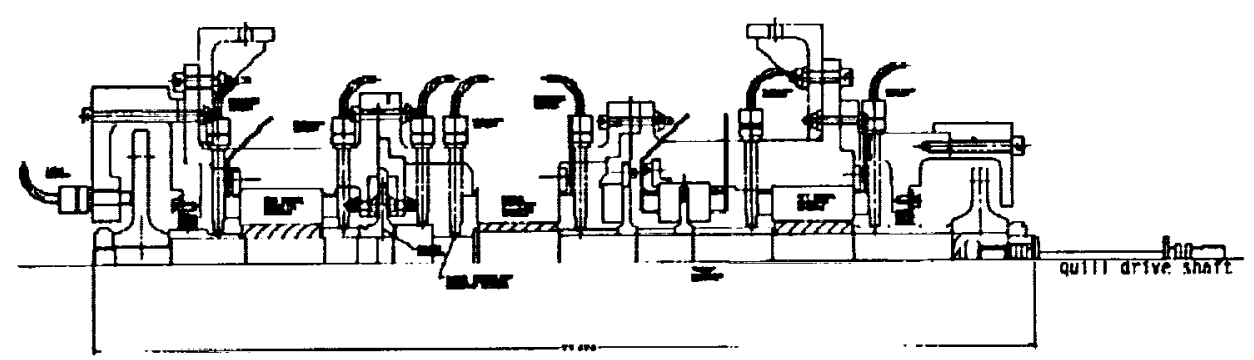

Figure 12. GE Single Spool Magnetic Bearing Test Rig

The test rig utilizes two radial magnetic bearings located fore and aft, an excitation radial magnetic bearing located at approximately mid-span, a thrust magnetic bearing, and a thrust excitation magnetic bearing. The forward direction is to the left. Radial auxiliary bearings are mounted out-board of the radial magnetic bearings. The radial auxiliary bearings are turbine engine class bearings, and the radial clearance between the shaft $O D$ and the bearing inner ring ID is equal to 10 mils. This precludes the possibility of damage to the radial magnetic bearings for overloads or rotor drop as the radial clearance of the magnetic bearings is equal to 20 mils. An axial auxiliary or bumper bearing is utilized to prevent damage to the thrust magnetic bearing.

Overhung disks located fore and aft simulate a fan and turbine and provide balance planes for mechanical balancing. An additional balance plane is available at the disk of the thrust excitation magnetic bearing. The rig is driven by a 20 HP electric motor through a quill drive shaft located at the aft end of the rotor.

General Electric will be developing a generic two shaft magnetic bearing test rig for use in dual rotor magnetic bearing engine studies. This will be accomplished by developing a shaft/case module and coupling case to permit expansion of the single shaft rig shown in Figure 12 into a two-shaft magnetic bearing test rig. The two shaft rig will provide experience and proven methodologies for use in the design of future twin spool magnetic bearing engines.

Figure 13 shows initial layouts for the two shaft magnetic bearing test rig. The lower configuration has a tuning spring (shown as an outer case over the right shaft/case module) which may be necessary to achieve dynamic coupling between the two shafts representative of two spool engine dynamics. 


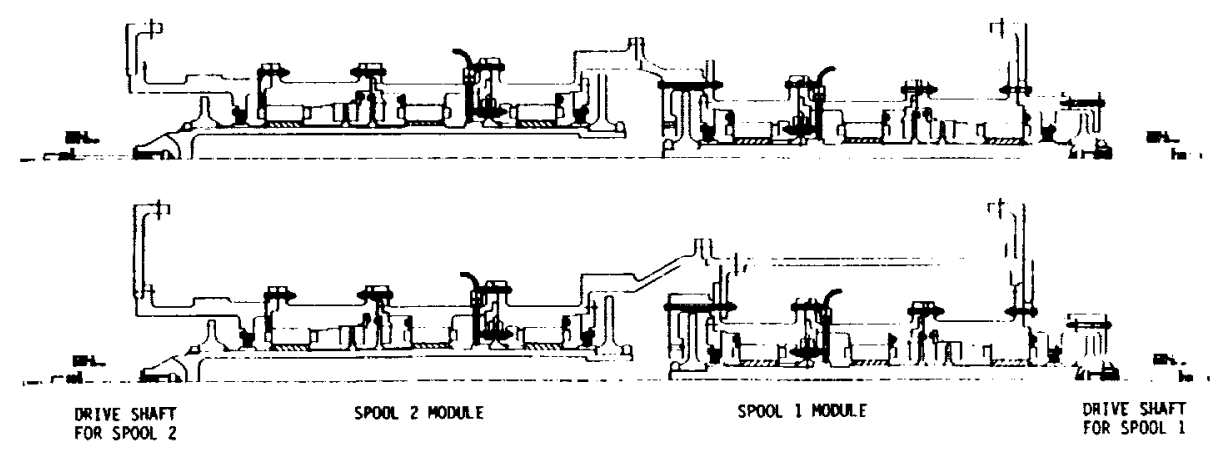

Figure 13. GE Twin Spool Magnetic Bearing Test Rig Configurations

\section{ACKNOWLEDGMENT}

The work reported herein dealing with controls, control algorithms, fault tolerance, and AMB system modeling and simulation was carried out using internal GE funding. This technology is being further enhanced under the auspices of an Army program awarded to GE Aircraft Engines by the Aviation Applied Technology Directorate (AATD), U.S. Army Aviation and Troop Command, Fort Eustis, Virginia 23604-5577, under contract DAAJ02-92C-0055. The contributions, suggestions, and encouragement of Bert Smith, the Army Program Manager for Magnetic Bearings, are greatly appreciated.

\section{REFERENCES}

1. Richter E., Anderson R. E., Severt C., The Integral Starter/Generator Development Progress, SAE Paper 920967, April 1992.

2. Storace, A. Turbine Engine Structural Efficiency Determination, AIAA 89-2571, July 1989.

3. Signorelli, R.A., Metal Matrix Composites for Aircraft Engines, NASA Technical Memorandum 83379, April 1983.

4. Composite Rotor Lamination for Use In Reluctance, Homopolar and Permanent Magnet Machines, U.S. Patent No. 4,916,346, Inventor: G.B. Kliman, assigned to GE, Dec. 28, 1987.

5. Method of Fabricating Composite Rotor Laminations for Use In Reluctance, Homopolar and Permanent Magnet Machines, U.S. Patent No. 4,918,831, Inventor: G.B. Kliman, assigned to GE, Oct. 20, 1989.

6. Lyons, J.P., MacMinn, S.R., and Preston, M.A., Flux/Current Methods For SRM Rotor Position Estimation, Proceedings of the 1991 IEEE Industry Applications Society Annual Meeting, Sept. 28-Oct. 4, 1991, Dearborn, MI, pp. 482-487.

7. Preston, M.A. and Lyons, J.P., A Switched Reluctance Motor Model with Mutual Coupling and Multi-Phase Excitation, IEEE Transactions on Magnetics, Vol. 27 No. 6, Nov. 1991, pp. 5423-5425. 
